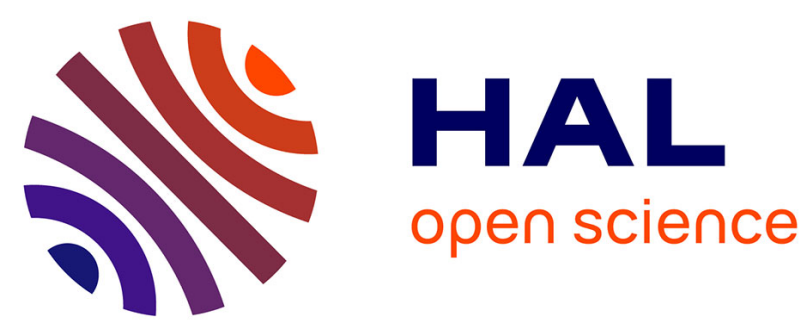

\title{
Conflictos, anclaje y territorialización: reflexiones a partir del caso mexicano
}

\author{
Patrice Mele
}

\section{To cite this version:}

Patrice Mele. Conflictos, anclaje y territorialización: reflexiones a partir del caso mexicano. Odile Hoffmann, Abelardo Morales. El territorio como recurso: movilidad y apropiación del espacio en México y Centroamérica, FLACSO, UNA, IRD, pp.67-86, 2018, 978-9977-68-300-3. halshs-02061616

\section{HAL Id: halshs-02061616 https://shs.hal.science/halshs-02061616}

Submitted on 6 Apr 2019

HAL is a multi-disciplinary open access archive for the deposit and dissemination of scientific research documents, whether they are published or not. The documents may come from teaching and research institutions in France or abroad, or from public or private research centers.
L'archive ouverte pluridisciplinaire HAL, est destinée au dépôt et à la diffusion de documents scientifiques de niveau recherche, publiés ou non, émanant des établissements d'enseignement et de recherche français ou étrangers, des laboratoires publics ou privés. 
Conflictos, anclaje y territorialización: reflexiones a partir del caso mexicano

Patrice Melé

\section{Introducción: ¿Un lugar nuevo para el estudio de los conflictos en México?}

El conflicto era consustancial al modo de funcionamiento del sistema de dirección política del Partido Revolucionario Institucional (PRI). Se puede incluso decir que la relación de fuerzas entre los grupos capaces de demostrar su capacidad para movilizar a la gente, su poder de convocatoria y su arraigo entre la población más pobre constituían una de las modalidades del sistema de tensiones dinámicas entre los grupos que caracterizaba al régimen del PRI.

Las investigaciones que pude llevar a cabo en el campo de la gestión urbana y patrimonial en lo referente a los últimos veinte años del siglo $\mathrm{XX}$ mostraban que el conflicto constituía la forma generalizada de las relaciones entre la acción pública y la población: en el momento del conflicto tenía lugar una fase de negociación con los grupos movilizados (Melé, 1994 y 1998). La gestión negociada de los conflictos sustituía a la concertación previa. Para los grupos movilizados o sus líderes, los conflictos constituían un medio para acercarse al poder y obtener el reconocimiento o el acceso a los recursos que distribuían las diferentes instancias del partido hegemónico. En general, la salida negociada del conflicto podía ser muy rápida, basada en la gran capacidad de integración de las diferentes instancias del partido. Es verdad que también existían movimientos que, para lograr arraigo local o constituir colectivos locales, emprendían el camino de la oposición, acercándose a otros grupos políticos y de militantes.

Con todo, en el funcionamiento tradicional del sistema del PRI, el conflicto constituía un medio de integración de la oposición, una forma de concertación a posteriori. Esa aparente funcionalidad del conflicto reposaba en una gran capacidad del sistema priísta para negociar y ofrecer compensaciones a los opositores.

En la actualidad, parece estar generalizándose otro tipo de conflicto. Se trata de situaciones frecuentemente vinculadas con proyectos públicos que implican la expropiación de terrenos o con proyectos privados de desarrollo de actividades económicas o de vivienda que son rechazados 
por los colectivos movilizados debido a las molestias, la contaminación o los posibles riesgos que conllevan dichos proyectos. Son conflictos a menudo prolongados y difíciles que el sistema político parece incapaz de encauzar y que, sin lugar a dudas, expresan el nuevo lugar que han tomado en México (al igual que en otros países) las controversias vinculadas con el medio ambiente, la calidad de la vida, los riesgos o la contaminación; pero las modalidades de la transición política mexicana condicionan marcadamente su forma particular y su intensidad.

En México, los autores de la literatura de investigación de los conflictos urbanos se interesan fundamentalmente por cuatro tipos de situaciones: a) los procesos sociales vinculados con las formas ilegales de urbanización (Azuela, 1989); b) las movilizaciones a causa de las catástrofes (Reguillo Cruz, 1999); c) los conflictos relacionados con el uso del espacio público (Duhau y Giglia, 2008), en especial, las tensiones vinculadas con la presencia de comerciantes ambulantes (Cross, 1998) o con la gestión de los espacios colectivos y con los intentos de cierre del espacio residencial; y d) las controversias relacionadas con el medio ambiente (Azuela, 2006; Bassols y Melé, 2001).

El paradigma del movimiento social (De la Peña et al., 1990; Massolo, 1992) y la presencia de militantes que buscan generar en los barrios populares las condiciones para el funcionamiento comunitario como alternativa a la lealtad al sistema del Partido Revolucionario Institucional (PRI) (Moctezuma, 1999), han marcado durante mucho tiempo la forma de conceptualizar los conflictos urbanos. Por lo demás, la manera de analizar la transición mexicana y las referencias a las luchas por el respeto del voto (Martínez Assad, 1985) han influido en las investigaciones sobre las situaciones de conflicto: mientras que antes se las interpretaba fundamentalmente como movimientos sociales, como modalidades de gestión negociada entre el partido-Estado (el PRI) y la población más desfavorecida (Montaño, 1976), en la actualidad, en algunos trabajos de investigación o ensayos políticos se considera que esas situaciones son reveladoras de un nuevo tipo de relación entre los colectivos movilizados y los poderes públicos, que son signos de estructuración de la sociedad civil (Álvarez Enríquez, 2004; Zermeño, 2005); en otros trabajos se subraya las fallas de los acuerdos institucionales del México de la transición (Azuela, 2006), expuestas a la luz del día por la generalización de los conflictos; y algunos antropólogos, finalmente, se interesan por las dimensiones culturales de las movilizaciones (Nivón, 2005 y 1998). Desde esa óptica, John Stolle-McAllister (2005) puso de manifiesto la incorporación en el seno de los movimien- 
tos de referencias locales y mundiales, modernas y tradicionales, que él caracteriza como producciones culturales de identidades "híbridas". Por lo general, la transición había sido interpretada como una "desectorialización' de las relaciones entre los poderes públicos y los grupos urbanos en la que las relaciones individuales de ciudadanía prevalecen sobre los pactos entre el Estado y los grupos urbanos organizados. Ahora bien, en el nuevo contexto pluralista, las relaciones de clientelismo entre los grupos movilizados y los partidos políticos parecen perdurar y constituir una de las constantes de las modalidades de arraigo local de los partidos políticos. Así, el análisis de los conflictos activos permite interesarse por las condiciones del surgimiento de colectivos que exigen el respeto del medio ambiente o del patrimonio y por sus relaciones con el nuevo régimen de acción pública.

En este texto se presentan las principales conclusiones de una investigación en México sobre dos situaciones de conflicto interrogadas a partir de las modalidades de territorialización ${ }^{2}$ vinculadas con los conflictos y las controversias, así como de la función del patrimonio y la del medio ambiente en el proceso de territorialización. Esos conflictos tuvieron lugar en el estado de San Luis Potosí. Se trata de dos conflictos marcadamente mediatizados: el primero está vinculado con la construcción de un confinamiento controlado de residuos peligrosos en Guadalcázar (de 1997 a 2011) y concluyó mediante una controversia jurídica en el seno del Tratado de Libre Comercio de América del Norte (TLCAN); y el segundo está todavía activo y vinculado con el funcionamiento de una mina a cielo abierto en Cerro de San Pedro, proyecto que empezó también en 1997.

\section{La movilización para salvar el Cerro de San Pedro}

El anuncio en 1996 de un proyecto de una mina a cielo abierto de oro y plata en el Cerro San Pedro (San Luis Potosí) por parte de la empresa Minera San Xavier, perteneciente al grupo canadiense New Gold Inc, desató un importante movimiento de oposición entre 1997 y 2007, fecha en la cual la producción empezó. Los grupos opositores siguen hasta la fecha intentando lograr el cierre de la explotación. La movilización culminó en el año 2002 mediante la organización de una consulta popular en la que 15,000 personas se pronunciaron en contra de

2 Para un análisis más precios de la dinámica de estos conflictos véase Patrice Melé, Transacciones territoriales, Patrimonio, medio ambiente y acción pública en México, UAM Iztapalapa, CEMCA, Juan Pablo Editor, 2014, 291 p. Traducción de Mario A. Zamudio Vega. Este texto propone una síntesis de las principales conclusiones de esta obra. 
la mina. En 2003, se creó un Frente Amplio Opositor que tenía como objetivo de reforzar la oposición al proyecto. A partir de esa fecha, los opositores se concentraron, por una parte, en la organización de fiestas, festivales y reuniones "culturales" en el Cerro y, por otra parte, en una batalla jurídica y política buscando el apoyo de la opinión pública y de las instancias nacionales de partidos políticos (véase figura 3.1).

La localidad del Cerro de San Pedro fue un importante pueblo minero que tuvo su auge en los siglos XVII y XVIII; se encuentra a 22 kilómetros del centro de la ciudad de San Luis Potosí y es considerada como el primer asentamiento de la ciudad. Con el cierre de la última mina en 1948 el pueblo entró en una fase de decadencia. Al principio de la movilización, en 1997, sólo residían en el pueblo 24 familias.

Figura 3.1. La movilización para salvar el Cerro de San Pedro (San Luis Potosi).

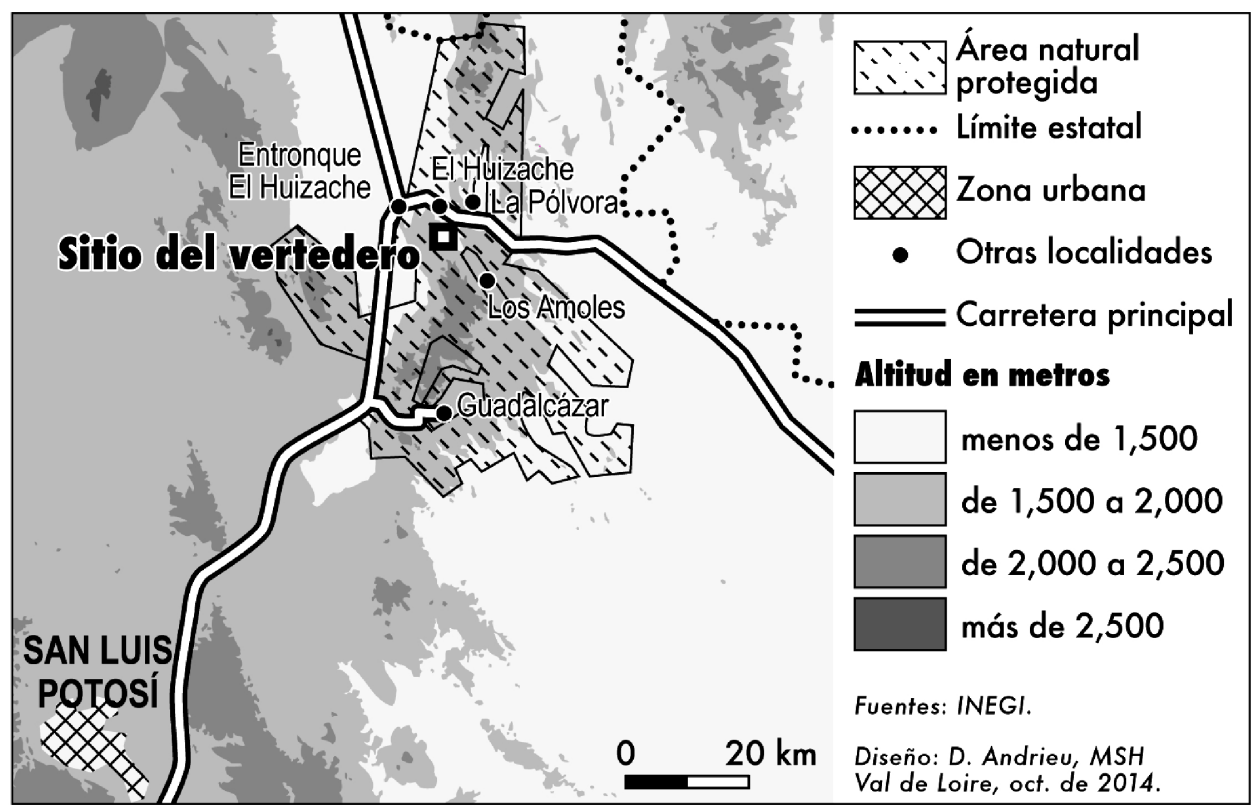

La controversia generó la constitución de un colectivo para la defensa y valorización de ese espacio en el cual jugaron un rol fundamental los "residentes secundarios" del pueblo, aquellos que conservaban una casa familiar u otros que habían comprado una casa de fin de semana. En efecto, la mayoría de los residentes permanentes de Cerro de San Pedro habían aceptado las propuestas de realojamiento o de compensación económica de la compañía minera. En la primera fase de la movilización este colectivo recurrió fundamentalmente a argumentos 
patrimoniales y pudo contar con el apoyo indirecto del INAH que intentó proponer la creación de una zona de monumentos. Fue solamente después del contacto con algunas asociaciones ambientalistas de San Luis Potosí que el colectivo recurrió a los argumentos relacionados con el medio ambiente (contaminación del suelo y del agua y destrucción del manto vegetal) para tratar de extender el espacio de movilización hasta la cercana ciudad de San Luis Potosí.

A pesar del conflicto y de algunas fases de inactividad - resultado de las batallas jurídicas llevadas por los opositores - la mina San Xavier ha logrado explotar el cerro de San Pedro. En 2016, la empresa ha anunciado el final de la explotación y actualmente (octubre, 2017) una parte de los trabajadores ha sido despedida y se ha anunciado la realización de trabajos de manejo y de aprovechamiento de los residuos.

\section{EI conflicto contra un confinamiento de residuos peligrosos en Guadalcazar}

El segundo caso estudiado es el conflicto contra la implantación de un confinamiento de residuos peligrosos en el sitio de la Pedrera, en el municipio de Guadalcázar, estado de San Luis Potosí (véase figura 3.2). En el contexto de un grave déficit de vertederos controlados en el país y en el estado, un grupo de empresarios de San Luis Potosí (Coterin) había empezado a recibir residuos sin autorización previa de almacenamiento (20 000 toneladas) en este sitio. En 1993 el confinamiento fue comprado por una empresa de Estados Unidos Metalclad que quiso gestionar los permisos de explotación a nivel federal y local.

En una primera fase, los habitantes más cercanos al sitio del vertedero fueron quienes comenzaron a informarse y organizarse después de haber descubierto la utilización del terreno. Las autoridades del municipio de Guadalcázar trataron por todos los medios de oponerse a la implantación del confinamiento a pesar de las autorizaciones otorgadas por las administraciones federales del medio ambiente (diversos recursos jurídicos, rechazo a autorizar el comienzo de las obras, etcétera). En el transcurso del año 1991, los opositores trataron de bloquear el sitio y el proyecto, informando a las diferentes autoridades administrativas y a los representantes políticos (gobierno del estado, federación, diputados locales y federales) de su oposición a tal actividad en "su territorio". En el septiembre del mismo año una toma del sitio por parte de 200 personas condujo al cierre del confinamiento por parte de las autoridades ambientales federales. Hasta 1993, fecha de la compra por 
parte de Metalclad y la adhesión a la causa por una asociación ecologista, la movilización fue esencialmente local. A partir de entonces, la controversia pareció cambiar de escala, Pro San Luis Ecológico, nuevo grupo ambientalista, funcionó como intermediario para diseminar la preocupación entre ciertos grupos que no tenían conocimiento directo del espacio en juego. Greenpeace México al igual que el Centro Mexicano de Derecho Ambiental (Cemda) desempeñaron una importante función para transferir y difundir la oposición en redes nacionales e internacionales y apoyar los opositores en el marco de los intentos de concertación organizados por las autoridades federales medioambientales.

Figura 3.2. El conflicto contra un confinamiento de residuos peligrosos en Guadalcazar (San Luis Potosí).

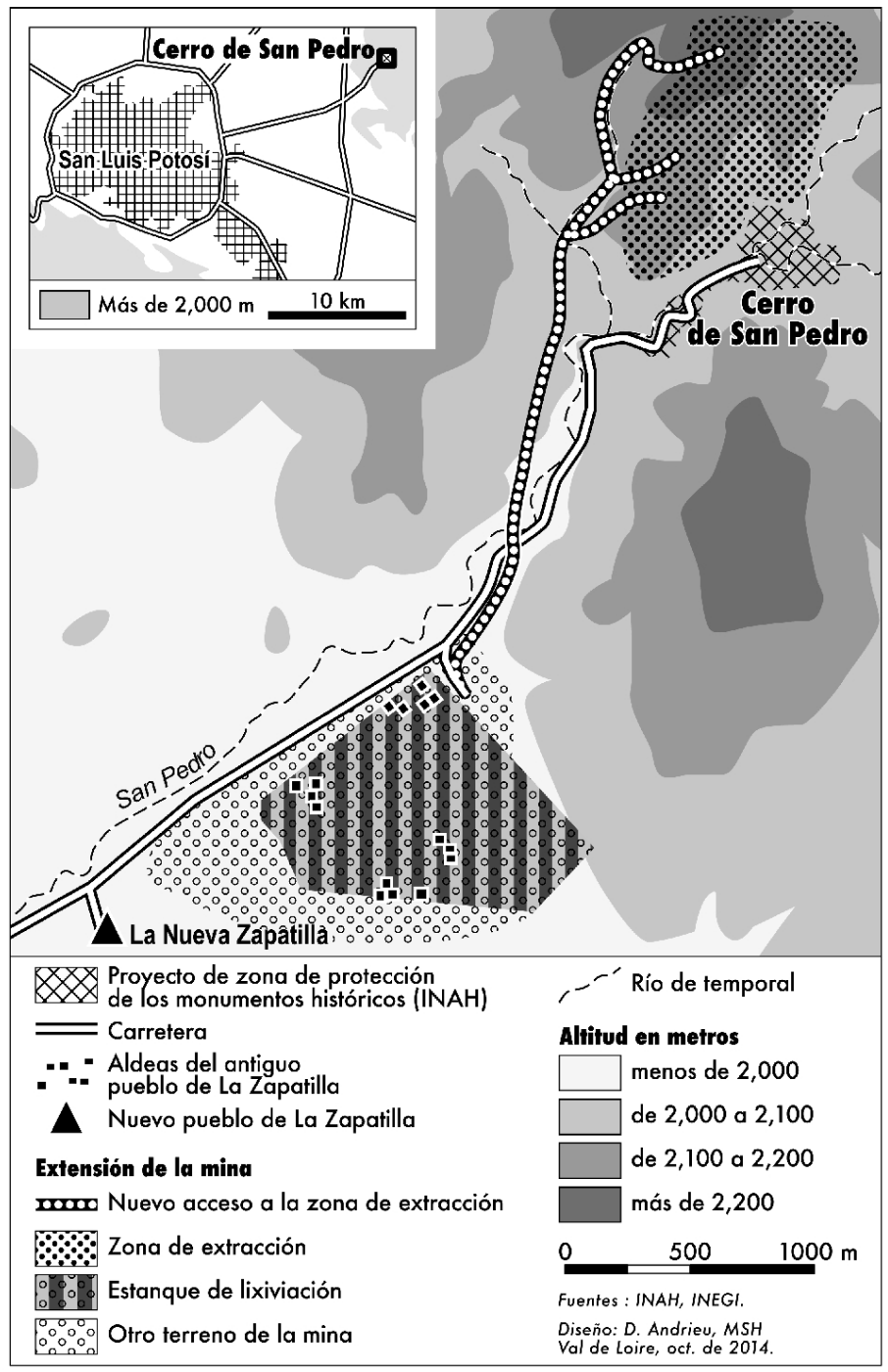


El intento para salir del conflicto mediante la elaboración de un acuerdo negociado entre las partes, a cargo de la Procuraduría Federal de Protección al Ambiente (Profepa) que obligaba a la empresa a integrar medidas de precaución suplementarias, se topó con la oposición de los poderes locales. La utilización claramente táctica que hizo el gobernador del estado de la creación de una zona natural protegida que incluía el lugar del proyecto de Guadalcázar fue presentada como una petición de los habitantes de la zona: con esta acción, el gobierno del estado estaba respondiendo a la inquietud social generada por el confinamiento no controlado de residuos peligrosos.

En enero de 1997, argumentando haber invertido 96 millones de dólares en el proyecto, la empresa Metalclad solicitó una resolución arbitral basada en el artículo 11 del Tratado de Libre Comercio de América del Norte (TLCAN) que garantiza la libre implantación de las inversiones extranjeras. La resolución arbitral condenó México a pagar mas de 15 millones de dólares. En 2001, después de que el Estado mexicano recurra en contra de este fallo, un juez canadiense confirmó la mayor parte de la condena de México, con el principal argumento que la declaratoria de zona natural por parte del Gobernador del estado de San Luis buscaba, más que proteger al medio ambiente, impedir la localización de la empresa.

\section{Conflictos como formas de resistencia de comunidades locales}

Una interpretación predominante de los conflictos - frecuentemente adoptada por los grupos movilizados - es la de una comunidad o una sociedad local que se resiste a una intrusión, a una imposición exterior. Tal interpretación está claramente presente en el caso de la implantación de proyectos industriales, mineros o de vertederos de residuos en zonas rurales o indígenas. Pero ese modelo de análisis también se encuentra en zonas urbanas, por ejemplo en el caso de la movilización de residentes de clases adineradas que viven en las orillas de las ciudades y se oponen al desarrollo de nuevos fraccionamientos que pongan en peligro su relación privilegiada con la "naturaleza" (Melé, 2003). El recurso a la retórica de la comunidad agredida refuerza la legitimidad de la movilización, mientras que, incluso en los contextos de la periferia de las ciudades, parece muy difícil describir las relaciones sociales como si se tratase de una comunidad ya existente antes del conflicto.

En el caso de los proyectos en zonas rurales o indígenas y frente a las movilizaciones de los habitantes, los promotores difícilmente pueden 
recurrir a la categoría de interpretación NIMBY ("not in my backyard", o sea "no en mi patio trasero" o en mi vecindario) que se utiliza para descalificar las reivindicaciones de los grupos locales y justificar la realización de acondicionamientos o proyectos "de utilidad pública" (Trom, 1999). Esa argumentación parece menos legítima en estos contextos, probablemente debido a la representación que se tiene de las relaciones supuestamente estrechas establecidas entre los grupos locales y su espacio, basada en el modelo de la comunidad rural, indígena o no. En efecto, estas presuponen no solamente cierta densidad de relaciones sociales en el seno del grupo sino también la apropiación legítima de su espacio de vida. A ese respecto, las grandes dificultades encontradas por las autoridades mexicanas del medio ambiente cuando trataron de oponer a las resistencias de las poblaciones locales un conjunto de argumentos creíbles sobre la necesidad de implantar una red de vertederos y de centros de tratamiento de residuos peligrosos parecen particularmente significativas.

En el orden simbólico, la necesidad - imperiosa y de evidente "utilidad pública", no obstante - de organizar el almacenamiento y tratamiento de residuos peligrosos tiene poco peso frente a las movilizaciones locales. Mientras que en los vertederos clandestinos se almacenan cantidades muy considerables de residuos peligrosos, el debate se centra en los peligros potenciales de unos eventuales vertederos controlados. Dada la imposibilidad de identificar a sus responsables, las movilizaciones en contra de los vertederos clandestinos tienen mucho más dificultades para acceder a la esfera pública que las movilizaciones de rechazo de los proyectos que hayan obtenido el acuerdo de las autoridades del medio ambiente. Los intentos de recurrir a la argumentación "nimby" para caracterizar y desacreditar la oposición de los grupos locales al almacenamiento de residuos producidos en otro lugar parecen tener poca influencia en la opinión pública. La falta de confianza en las autoridades del medio ambiente y en las empresas - frecuentemente extranjerasque proponen establecer vertederos descalifica esos proyectos, de los que se sospecha que son para tratar residuos peligrosos importados.

Sea cual fuere el objeto del conflicto, sea cual fuere la coherencia de los grupos locales antes del conflicto, lo que está en juego - en especial en una zona rural - es mucho más que un rechazo vinculado con un eventual síndrome nimby. Es, antes bien, la construcción o reactivación de identidades locales en el conflicto. Así, en resonancia local de ciertos conflictos se puede ver un elemento de resistencia de las sociedades lo- 
cales frente al centralismo o a la apertura económica. En San Luis Potosí los dos conflictos ambientales más importantes de los últimos años conciernen a la implantación de empresas extranjeras, una canadiense y la otra estadounidense, cuyos proyectos habían sido aprobados por las autoridades federales. El eco que se hizo a esas movilizaciones en el campo político, la esfera mediática y entre la población en general se puede interpretar también como una resistencia de la sociedad local frente a lo que se percibe como una imposición del poder central. El contexto político local se vio marcado por una precoz revuelta electoral que se oponía a las decisiones del Estado-partido prísta y por una gran inestabilidad política, alrededor, entre otras, de la figura de Salvador $\mathrm{Nava}^{3}$. Hasta la fecha existe un debate sobre las influencias del movimiento navista en la conflictividad que suele caracterizar las cuestiones relativas al medio ambiente en San Luis Potosí. Sea lo que fuere, ciertos antiguos militantes navistas se convirtieron en líderes ambientalistas y la sensibilidad local a los ataques contra el gobierno federal está impregnada del recuerdo de las movilizaciones del pasado.

Una parte de la lucha ambiental recurre a la misma retórica que la político-electoral, a saber la de la revuelta de la sociedad local frente a las imposiciones del exterior. Pero quizá sea necesario relativizar esa influencia de la lógica política que opone la legitimidad de lo local frente al centro, recordando, por una parte, que el movimiento navista también era una gran coalición de partidos, grupos, militantes y simples ciudadanos comprometidos en las luchas locales y, por otra parte, que el navismo no fue la única fuente del movimiento ecologista. Este último está profundamente marcado por la presencia de militantes de izquierda y especialistas en el medio ambiente provenientes de la Universidad de San Luis Potosí.

Cuando se observa de más cerca, se ve que el marco de interpretación "revuelta de sociedades o de comunidades locales" parece insuficiente para explicar la complejidad de las situaciones de conflicto. La afirmación anterior no significa deslegitimar a los grupos movilizados ni reducir la amplitud de las movilizaciones locales a un pequeño grupo

3 Salvador Nava, precursor de las luchas por el pluralismo político y presidente del municipio de San Luis Potosí entre 1959 y 1961 y entre 1983 y 1985, se opuso a las imposiciones electorales del partido hegemónico y logró organizar un amplio movimiento de apoyo a su candidatura y de resistencia civil frente a los fraudes e imposiciones electorales; sin embargo, no logró tener acceso al gobierno del estado, a pesar de la intensa movilización desencadenada por sus candidaturas en 1961 y 1991. 
de líderes o militantes ecologistas o políticos. Se trata más bien de subrayar la necesidad de entender mejor las modalidades de constitución de los colectivos movilizados para defender ciertas cualidades de un espacio particular. En efecto estos colectivos no siempre están constituidos sobre una base local, sino frecuentemente como una red de muchos planos. Para entender a cabalidad estos movimientos, es necesario alejarse del a priori que considera que los grupos locales están estructurados conforme al modelo de la comunidad. Es necesario tomar en serio los debates y las oposiciones internas que no son forzosamente descifrables a partir de una distinción entre los que poseen una conciencia ecológica o política y los que están "vendidos" a las autoridades o a los promotores del proyecto. En varios casos por ejemplo, cuando un posible reparto de tierra está en juego, se nota la oposición entre los titulares de los derechos de uso de las tierras comunales y otros miembros del mismo pueblo, entre diferentes grupos de ejidatarios o entre varios ejidos.

Muy frecuentemente, los colectivos movilizados se presentan como una alianza de miembros de una comunidad local afectada por un proyecto y que han buscado, en la ciudad más cercana o en la ciudad de México, el apoyo de militantes o simpatizantes de la causa ambiental para la defensa de la integridad de su espacio de vida. Pero se trata de una relación dinámica. En ciertos casos, los militantes o expertos exteriores al grupo local desempeñan una función fundamental en la movilización. Incluso son ellos quienes impulsan la organización y reclutan a residentes locales para dar un arraigo a su oposición a ciertos proyectos o ciertas acciones de los poderes públicos. Tal es el caso de los dos conflictos estudiados en el estado de San Luis Potosí, en los que los militantes de las asociaciones de ecologistas de la capital del estado actúan, además, como intermediarios entre el movimiento local y los grupos nacionales que apoyan y difunden noticias sobre los conflictos en los medios de comunicación.

Los momentos de controversia o conflicto son momentos durante los que se renegocia también el lugar que ocupan aquellos miembros de la comunidad que han emigrado, en cuanto se discute su "derecho" a intervenir en los asuntos locales. Observar estas situaciones ofrece la oportunidad de comprender las complejas relaciones entre los residentes y los no residentes. Ciertos emigrados consideran que siguen formando parte de la comunidad y adoptan posiciones de defensores del patrimonio, el paisaje o el medio ambiente, mientras que ciertos residentes se preocupan esencialmente por las repercusiones económi- 
cas de un proyecto. Consecuentemente, las situaciones de movilización estudiadas se deben entender como controversias sobre la legitimidad de la toma de posición de los diversos sujetos y actores sociales sobre el futuro de un espacio dado.

Por lo mismo, es importante interesarse por la constitución de los grupos que intervienen en el conflicto, que llamamos "colectivos" para subrayar que no preexisten al conflicto. Los colectivos no están forzosamente territorializados; funcionan en red y pueden integrar a emigrados salidos del grupo local, y también a militantes, simpatizantes y expertos movilizados. El colectivo se constituye y se unifica en la defensa de un espacio cargado de valores mediante la movilización.

También me parece necesario recordar que la representación del espacio en juego (como "espacio natural", por ejemplo) no es preexistente al conflicto; al contrario, es el resultado de un esfuerzo colectivo por construir la legitimidad de la movilización. Los intercambios, interacciones y acciones comunes entre diferentes personas situadas en posiciones diferentes en relación con el espacio en juego contribuyen a modificar las representaciones de éste. Consecuentemente, los conflictos constituyen situaciones durante las cuales las cualidades y valores atribuidos a un espacio son renegociados en la interacción de los opositores con los actores públicos.

En las situaciones de conflicto se puede observar otro proceso de valorización de los espacios en juego, ya no entre opositores y actores públicos o empresas sino en el seno mismo del colectivo de opositores. Los expertos y los militantes ecologistas o políticos contribuyen a arraigar localmente los valores patrimoniales y ambientales que se vuelven recursos estratégicos para las poblaciones movilizadas; a la vez, los nuevos valores atribuidos al espacio desempeñan una función cognitiva que permite elaborar nuevas visiones del espacio en conflicto.

La solidez y el arraigo de la movilización, el peso de los grupos locales y la amplitud del debate en los escenarios regionales, nacionales o internacionales son, evidentemente, muy diferentes según el contexto y lo que sea que esté en juego. El análisis de las situaciones concretas deja ver la constitución de redes de varios planos de actores movilizados para la defensa del espacio local, así como un trabajo de producción de las cualidades del espacio a las que se puede recurrir para nutrir la argumentación. 


\section{Dimensiones espaciales y territoriales de los conflictos}

Salir del marco explicativo de la comunidad agredida para interesarse por la constitución de los colectivos en el conflicto no implica que al territorio no se le otorgue un lugar de capital importancia en el análisis de los conflictos. Proponemos desplazar la mirada para tratar de comprender, no el enfrentamiento entre un territorio - definido como lo que ya está ahí y resiste- y un proyecto, sino los procesos mismos de territorialización y localización — la modalidad del establecimiento de una instalación, una empresa o un proyecto inmobiliario en cierto espacio-. Este nuevo enfoque permite analizar las dimensiones espaciales y territoriales de los conflictos y las controversias e interpretar esas situaciones como luchas por la apropiación legítima de un espacio. Los momentos de conflicto son momentos de elaboración, en la controversia, de una definición pragmática de los usos legítimos del espacio. Las situaciones analizadas confortan la hipótesis de la existencia de un proceso de valorización de un territorio por parte de los colectivos movilizados en el momento mismo de la controversia. Los colectivos son alianzas heteróclitas entre residentes, migrantes, naturalistas y militantes ambientalistas y/o partidistas. No están necesariamente arraigados en el espacio en juego ni tienen siempre la estabilidad de una comunidad de militantes, pero no por ello dejan de constituir un campo en cuyo seno se difunden, actualizan o producen clasificaciones del territorio a partir del conjunto de los recursos disponibles. En la elaboración de la argumentación se recurre a las prácticas y experiencias cotidianas, también a los arraigos simbólicos de las comunidades locales, sean indígenas, populares o agrarias, e incluso a los saberes y posiciones de los ambientalistas o los ecologistas. Además, ponen a prueba la capacidad de las declaraciones de intención de las políticas públicas y las disposiciones jurídicas que protegen las especies naturales o los espacios para movilizar a los actores institucionales y la fundamentación jurídica que ostentan.

Identificar la función de esos recursos simbólicos, argumentativos o jurídicos no significa adoptar el marco de análisis del actor-red propuesto por la sociología de las ciencias y las técnicas, que los considera como portadores de la acción con el mismo derecho que los actores humanos que participan en una controversia; no obstante, se debe subrayar que esa posición ha tenido el gran mérito de sacar a la luz del día la función de los valores y declaraciones de intención de las políticas públicas, sin que sea necesario recurrir a las nociones de las representaciones o las ideologías, sino adoptar una metodología de observación pragmática de su presencia en situación (Callon y Law, 1997). 
El enfoque que proponemos permite observar la complejidad de las relaciones entre los grupos movilizados y el espacio en juego. Cada situación de conflicto se puede describir como la tensión entre la preocupación de ciertos componentes de la sociedad local, mientras que otros se resisten a participar en la controversia. También es posible analizar las cosas de otra manera, a saber que, para lograr su exitoso anclaje (lo que llamamos "localización"), un proyecto debe ser capaz de unir a grupos variados (líderes, notables y residentes que esperan beneficios de una actividad nueva, etc.). En el contexto mexicano anterior a la transición política, el sistema priísta aseguraba cierta eficacia de las alianzas entre los promotores de un proyecto y los políticos. La propia supervivencia de los grupos políticos dependía de su eficacia para controlar a los grupos locales y una alianza con un grupo político podía garantizar que un promotor encontrase los relevos locales adecuados. Además, frecuentemente los propios promotores estaban ligados a algunos grupos políticos y, por lo demás, la aceptación o resistencia a los proyectos podían interpretadas como la manifestación de la capacidad de acción de ciertos líderes. La pluralidad de la oferta de los grupos políticos no eliminaba el conflicto a todas las escalas, aunque sí garantizaba que se pudiera llevar a cabo cierta regularización en el seno de las diferentes instancias que regulaban las tensiones que constituían la gran plasticidad del sistema de poder. En ese contexto, se podía analizar los conflictos y controversias como una manifestación de las luchas de poder entre los grupos que buscaban mantener o conquistar posiciones locales; sin embargo, algunos de mis trabajos han mostrado que también se podía estudiar las situaciones de conflicto desde la perspectiva de colectivos locales movilizados que buscaban, pragmáticamente, encontrar una "cobertura política" para adquirir una mayor eficacia en el escenario político nacional (Melé, 1990).

Las situaciones de conflicto ponen en evidencia las dificultades de la elaboración de un nuevo arreglo institucional en el contexto de una transición que también se caracteriza por la descentralización, sin que ésta venga acompañada del establecimiento de procedimientos de negociación entre los diferentes ámbitos de poder. En lo concerniente a las modalidades de ajuste mutuo entre los actores institucionales, el caso mexicano se podría caracterizar como el pasaje de un "alineamiento colectivo" a una fragmentación (Cabrero, 2000, p.197). A pesar de una mayor juridificación de las cuestiones ambientales y patrimoniales, la capacidad de las autoridades locales para actuar sobre la dinámica de las actividades económicas sigue siendo muy poca. Este análisis confirma las conclusiones de Antonio Azuela, quien considera que los conflictos — en especial el de Guadalcázar — hacen aparecer un 
"débil desarrollo institucional" de las formas locales de gobierno que, según él, constituye un obstáculo real al establecimiento de una gestión ambiental democrática (Azuela, 2006, p.11).

\section{La imposible generación de asentimiento}

En los casos de conflictos en México que hemos analizados, vemos que las tentativas de mediación de las autoridades ambientales no permitieron reducir los conflictos. Antes bien, se observa el establecimiento de dos tipos de conflictos: los que se podrían calificar como conflictos de "implantación" de alguna actividad o infraestructura y los que corresponden a la negociación de las molestias o los riesgos de actividades existentes. En el segundo caso, los opositores pueden adquirir conciencia rápidamente de que no obtendrán la reubicación de las actividades a las que se oponen y, por lo tanto, deben aceptar una negociación sobre los impactos, las molestias y los riesgos. Los dos conflictos estudiados, en San Luis Potosí, revelan también la incapacidad de las autoridades que tratan del medio ambiente, tanto federales como del estado, para generar confianza en sus actos.

Para los opositores, las autoridades a cargo del medio ambiente o del patrimonio son responsables, porque deberían declarar que los proyectos son incompatibles con la calidad de la vida de los habitantes y con el mantenimiento de la integridad del medio ambiente o la del paisaje. Aún si, en los casos analizados, los dos proyectos habían negociado exitosamente la aprobación de su declaración de impacto ambiental, los opositores sospechan sistemáticamente que las autoridades a cargo del medio ambiente están en colusión con los promotores o que otorgan prioridad al desarrollo económico. Para neutralizar los efectos de la mediación ambiental, los habitantes más movilizados, apoyados por los militantes, recurren a estrategias que buscan que se considere a las autoridades del medio ambiente, no como aliados que garantizan la inocuidad de los proyectos, sino como adversarios, cómplices de las empresas extranjeras cuya implantación parece que buscan facilitar.

Al mismo tiempo, es importante recordar que, paralelamente al fortalecimiento de la capacidad de acción de las instituciones del medio ambiente, los textos oficiales emitidos en los últimos veinte años introdujeron contrafuegos procedimentales para evitar que las medidas ambientales constituyese un freno a las inversiones. Así, las instituciones del medio ambiente son objeto de sospecha por gran parte del aparato gubernamental de adoptar una actitud maltusiana o una alianza con los ecologistas y naturalistas, y por los ambientalistas de priorizar 
ante todo los intereses de los promotores. Bloqueadas entre estos dos frentes, las autoridades del medio ambiente están sometidas a fuertes presiones en el marco de los conflictos o de las controversias mediáticas. De hecho, las instituciones dedicadas al medio ambiente (a nivel federal y estatal) han dado pruebas de su inocuidad frente el desarrollo de los grandes proyectos.

Las situaciones analizadas muestran también el difícil posicionamiento de las instancias federales encargadas de la protección del patrimonio y el medio ambiente. En principio, la propia concepción de su acción busca más controlar los impactos, y hacer que se cumplan las normas, que definir las actividades compatibles o no con el medio ambiente y el patrimonio. En el terreno del medio ambiente, ese segundo objetivo remite a una actividad de planificación ecológica del territorio que sólo existe en el papel.

En primera línea frente a las críticas de los opositores, las autoridades del medio ambiente intentan aportar la prueba, no solamente de que aplican de manera irreprochable la legislación, sino también de que manifiestan la voluntad de controlar el proyecto o la actividad de la manera más estrecha posible. A ese respecto, las condiciones impuestas al funcionamiento de los proyectos son otras tantas manifestaciones de la capacidad de las autoridades a cargo del medio ambiente para obligar a los inversionistas a tomar en cuenta las normatividades ambientales. Lo que muchas veces busca más construir la compatibilidad de los proyectos con el territorio que impedir su localización.

\section{Conclusiones}

En los casos a que se ha recurrido para este estudio se observa una tensión entre el proceso de territorialización - construir un espacio a medida que se defiende frente a un proyecto dado- y la voluntad de repliegue de los valores ambientales sobre ciertos objetos (monumentos). En ciertos casos, esta tensión puede desembocar en una verdadera deslocalización del valor ambiental. Una ilustración "ejemplar" de esta deslocalización lo constituye la propuesta de construir equivalencias que permitirían compensar en otro lugar los ataques al medio ambiente en un lugar dado. Si lo que está protegido no es el lugar mismo o un paisaje en particular sino un "objeto ambiental", entonces es posible compensar la deforestación y destrucción del paisaje con árboles plantados en otro lugar, o intercambiar un derecho de construcción o parcelamiento por la realización de un parque ecológico a cierta distancia, entre otros ejemplos. 
La extensión de los valores ambientales y patrimoniales a ciertos espacios procede por generalización. Implica la "no reductibilidad" a objetos y la imposibilidad de medidas de compensación deslocalizadas. Tanto para los promotores de los proyectos como para las autoridades del medio ambiente, la declaración ambiental y patrimonial debe disociar los distintos impactos que podrá tener un proyecto para que se logre condicionar detalladamente las prácticas. Para la compañía minera del Cerro de San Pedro, por ejemplo, las restricciones ambientales y patrimoniales son reductibles a cinco especies protegidas y a dos monumentos; a las medidas de control de la calidad del aire y del agua y de los riesgos de contaminación; a los procedimientos de reducción de los riesgos; y al establecimiento de una estrategia de comunicación y de negociación con las poblaciones cercanas.

Esta investigación ha permitido poner de manifiesto las relaciones entre el conflicto y la aplicación de las políticas públicas en el contexto mexicano. Se puede considerar que las controversias fortalecen la capacidad de las autoridades del medio ambiente y del patrimonio para restringir las actividades que afectan al medio ambiente. También se ha observado el establecimiento, bajo la presión de los conflictos, de una mediación ambiental que busca generar las condiciones de localización de las actividades, tomando a su cargo no solamente el control de los impactos sobre el medio ambiente, sino también las necesarias negociaciones con las poblaciones afectadas. Las modalidades de la mediación ambiental proceden por lo general mediante la reducción del valor ambiental a sus componentes, lo cual permite considerar entonces la gestión del ambiente mediante la apropiación, la privatización o bien, mediante proyectos que, en el marco de contratos formales o informales, pueden beneficiarse de certificaciones ambientales.

Ahora bien, los residentes movilizados, los militantes y los expertos naturalistas se oponen a esa acción ambiental pragmática en nombre de un deber ser del espacio, deber ser inscrito localmente mediante la clasificación jurídica del espacio. El caso mexicano muestra que el ordenamiento del espacio por zonas no es suficiente para lograr la territorialización de las políticas públicas del patrimonio o el medio ambiente. Pero también muestra que la delimitación de las zonas no deja de tener efectos: se puede recurrir a ella en el marco de las movilizacione. Mientras que, en otros contextos nacionales, la acción pública busca generar la adhesión de los actores a la clasificación del espacio (los perímetros definidos son pretextos para el establecimiento de la coordinación entre los actores), en México pareciera que la socialización de 
la clasificación jurídica del espacio sólo tuviera lugar en el marco de los conflictos y las controversias. En ese caso, la clasificación jurídica del espacio desempeña la función de un recurso para los actores que demandan el fortalecimiento de las acciones de protección de ciertos subconjuntos espaciales.

\section{Bibliografía}

Álvarez Enríquez, L. (2004). La sociedad civil en la ciudad de México, actores sociales, oportunidades políticas y esfera pública. México: Plaza y Valdés, UNAM.

Azuela, A. (1989). La ciudad, la propiedad privada y el derecho. México: El Colegio de México.

Azuela, A. (2006). Visionarios y pragmáticos. Una aproximación sociológica al derecho ambiental. México: UNAM-Instituto de Investigaciones Sociales/Fontanamara.

Bassols, M. y Melé, P. (coords.), (2001). Medio ambiente, ciudad y orden jurídico. México: Miguel Ángel Porrúa / UAM-Iztapalapa.

Cabrero Mendoza, E. (2000). Usos y costumbres en la hechura de las políticas públicas en México. Límites de las policy sciences en contextos cultural y políticamente diferentes. Gestión y Política Pública, 9 (2), 189-229.

Callon, M. y Law, J. (1997). After the Individual in Society: Lessons on Collectivity from Science, Technology and Society. Canadian Journal of Sociology, 22 (2), 165-182.

Cross, J. C. (1998). Informal Politics: Street Vendors and the State in Mexico City. Estados Unidos: Stanford University Press.

De la Peña, G., Durán, J., Escobar, A. y García de Alba, J. (1990). Crisis, conflicto y sobrevivencia, Estudios sobre la sociedad urbana en México. Guadalajara, México: Universidad de Guadalajara, CIESAS.

Duhau, E. y Giglia, A. (2008). Las reglas del desorden: habitar la metrópoli. México: Siglo XXI. 
Martínez Assad, C. (Coord.). (1985). Municipios en conflicto. México: Instituto de Investigaciones Sociales.

Massolo, A. (1992). Por amor y coraje, mujeres en movimientos urbanos de la ciudad de México. México: El Colegio de México.

Melé, P. (1990). Geopolítica del estado de Puebla: elecciones, poderes y conflictos. México: Universidad Autónoma de Puebla-Instituto de Ciencias, Gernika.

Melé, P. (1994). Puebla urbanización y políticas urbanas. México: Universidad Autónoma de Puebla, Universidad Autónoma Metropolitana-Azcatpotzalco.

Melé, P. (1998). Patrimoine et action publique au centre des villes mexicaines. Francia, París: Institut des Hautes Études de l'Amérique Latine, Presse de la Sorbonne Nouvelle.

Melé, P. (2003). Conflits urbains pour la protection de la nature en une métropole mexicaine. En Melé, P., Larrue, C. y Rosemberg, M. (coord.), Conflits et territoires, Perspectives Villes et territoires. (pp. 103-120). Tours, Francia: Presses universitaires FrançoisRabelais.

Melé, P. (2006). La producción del patrimonio urbano. México: Publicaciones de la casa Chata.

Moctezuma Barragán, P. (1999). Despertares, comunidad y organización urbano popular en México, 1970-1994. México: UAM, Universidad Iberoamericana.

Montaño, J. (1976). Los pobres de la ciudad en los asentamientos espontáneos. México: Siglo XXI.

Nivón Bolán, E. (1998). Cultura urbana y movimientos sociales. México: UNAM/Conaculta.

Nivón Bolán, E. (2005). La política de la identidad en los movimientos sociales. El caso de la defensa de la tierra en el oriente de la ciudad de México. Antropologías y estudios de la ciudad, (1), 125-145.

Reguillo Cruz, R. (1999). La construcción simbólica de la ciudad. Sociedad, desastre y comunicación. Guadalajara: ITESO.

Stolle-McAllister, J. (2005). Mexican Social Movements and the Transition to Democracy. Jefferson. Estados Unidos: McFarland and Company, Inc., Publishers. 
Trom, D. (1999). De la réfutation de l'effet Nimby considérée comme une pratique militante. Revue Française de Science Politique, 49 (1), 31-50.

Zermeño, S. (2005). La desmodernidad mexicana y las alternativas a la violencia y a la exclusión en nuestros días. México: Océano. 
